\title{
Using Fly Ash for Removal of Hazardous Substances in Water: An Undergraduate Environmental Chemistry Research Project
}

\author{
Brianna Lambes and Shahrokh Ghaffari \\ Ohio University-Zanesville \\ Zanesville, OH 43701
}

Received: October 2, 2006 Accepted: November 20, 2006

\begin{abstract}
Fly ash obtained from a coal burning power plant was used to separate dissolved component of unleaded fuel from water using column chromatography. The results of this study indicate complete removal of the unleaded fuel from water. Eluted water collected from fly ash packed column has no odor. A successful field test at a larger scale shows the real environmental benefit of using this approach for removal of environmentally hazardous materials.
\end{abstract}

\section{INTRODUCTION}

A major environmental concern that all communities face is cost-effective and timely removal/cleaning up of spilled or leaked hazardous substances in water or other essential systems. Finding innovative and cost-effective technologies to accomplish this task will benefit our global village. Fly ash, a by-product of the combustion of coal power plants, is a promising material that is readily and inexpensively available.

Coal is the major fuel source $(57 \%)$ for generating electricity in the US. Nearly $90 \%$ of electricity produced in Ohio is generated by burning coal. One of the coal combustion products (CCPs) is fly ash. According to data from American Coal Ash Association, nearly $75 \%$ of fly ash produced in USA ended up in landfills. In Ohio, $80 \%$ of the fly ash is being placed in landfills [1].

Several studies related to the surface chemistry of the fly ash and its interaction with some of the organic chemicals poly cyclic aromatic hydrocarbons, PAH's, have been conducted. These studies have, to varying degrees, concluded that the adsorption of the PAH's are dependent on the physical and/or chemical composition of the surface on which they are adsorbed [2 - 5]. The research indicates that fly ash is a great platform for removal of heavy metals from wastewater [6]. It has also shown promise as a soil stabilizer and erosion blocker [7].

The intent of this innovative approach for using fly ash was to study the capability and capacity of fly ash for removal of dissolved components of gasoline from water. A pilot field test done by Enviro-Mont at Twin Falls, Idaho indicates a very promising method for removal of spilled fuel from underground water.

\section{EXPERIMENTAL PROCEDURE}

All chromatographs were collected by running one micro liter of each sample through a Schmadzo GC-14A gas chromatoghraph (GC) with Restek, RTX-5, crossbond $15 \mathrm{~m}, 5 \%$ diphenyl, 95\% diethypolysilioxane, capillary column. The instrument setting is as following; initial temperature, $50.0^{\circ} \mathrm{C}$; after 2 minutes delay time the temperature increase rate, 12.0 ${ }^{\circ} \mathrm{C} / \mathrm{min}$; final temperature, $170{ }^{\circ} \mathrm{C}$; chart speed $1 \mathrm{~cm} / \mathrm{min}$, and total run time 10 minutes In each of the following steps, two or more injections per samples were made.

1. To obtain the background chromatograph, one micro liter of deionized water is injected into the GC (Figure 1a). 


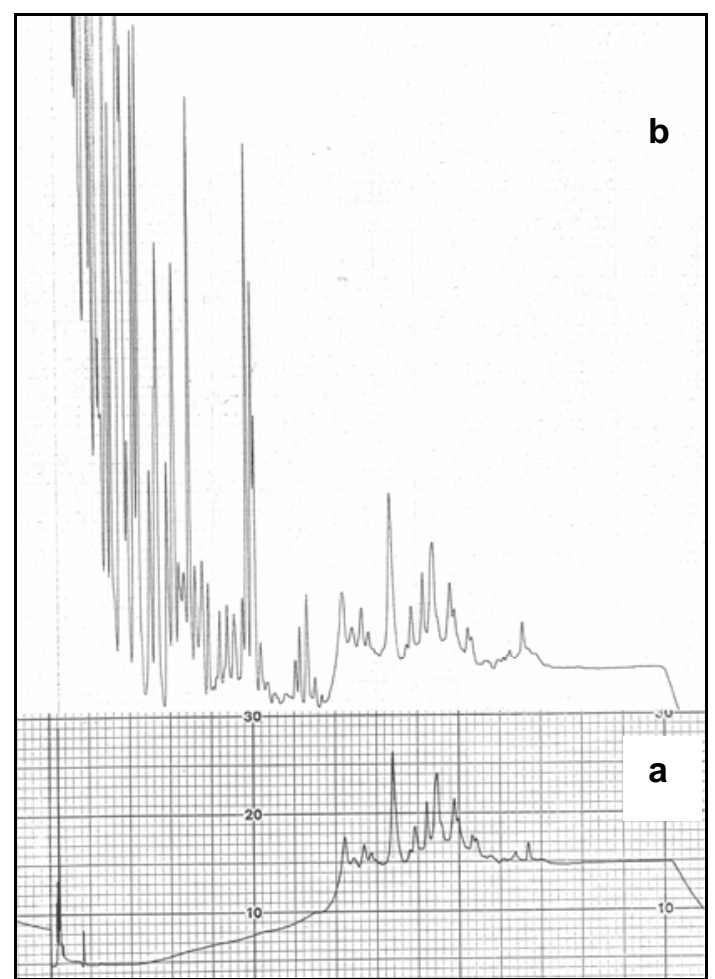

Figure 1. a) Chromatograph of deionized water, b) chromatograph of unleaded fuel.

2. To obtain the chromatograph of unleaded fuel obtained from local gas station, one micro liter of fuel is injected into the GC (Figure 1b).

3. To obtain water/fuel mixture, one milliliter of fuel is added to each of four separatory funnels containing $100 \mathrm{~mL}$ of deionized water. The mixtures are vigorously shaken and allowed to sit for 2 hours for complete separation of undissolved components of gasoline.

4. The aqueous layer of each separatory funnel is separated, and one micro liter of each sample is injected into the GC (Figure 2a).

5. Four columns $(11 \times 30 \mathrm{~mm}$ glass $)$ are packed with $1,3,5$, and 7 grams of fly ash. Then each column is washed three times with $100 \mathrm{~mL}$ portions of deionized water to remove any component of fly ash that may be eluted from columns during the experiment.

6. Water from the third washing is collected and one micro liter is injected into the GC to obtain a blank chromatograph (Figure 2b).
7. The collected water phase from each separatory funnel, step 3 , is run through a column with different amount of pre-washed fly ash and eluent aqueous sample from each column is collected separately.

8. One micro liter of collected sample is run through the GC (Figure 2c).

\section{RESULTS}

As the chromatograph Figure $1 \mathrm{~b}$ indicates, with comparison to chromatograph Figure 1a, there are picks that appear in both water and fuel chromatograms. Later testing has indicated that the same picks appear when sample of air was injected. No further investigation was done. However, in future studies water should be removed from all samples using small portion of cyclohexane to prevent any possible damage to the column.

Comparing chromatograph Figures $2 a$ with $1 a$ indicates that i) not all components of fuel are dissolved in water and ii) from those components that dissolved their solubility's vary.

After washing the fly ash three times with water there are no fly ash's component is leaving the column. The chromatograph Figure $2 b$ is similar to chromatograph of deionized water (Figure 1a).

The chromatogram Figure $2 \mathrm{c}$ shows complete removal of dissolved fuel components in water by fly ash. The lowest amount of fly ash used is 1 gram for one milliliter of fuel used. The exact minimum amount of fly ash required for complete removal of fuel per milliliter of fuel used depends on the kind of fly ash or fuel.

\section{FURTHER STUDIES}

To determine the ideal amount of fly ash required for removal of known amount of petroleum, each step described in above method will be repeated until the amount of un-adsorbed petroleum remains constant. This methodology can be employed to analyze other petroleum products as well as other fly ashes from different sources.

Once the capability and capacity of fly ash for removal of petroleum is established, other undesirable environmental substances such as hydrogen sulfide or heavy metal can be studied using a simi- 


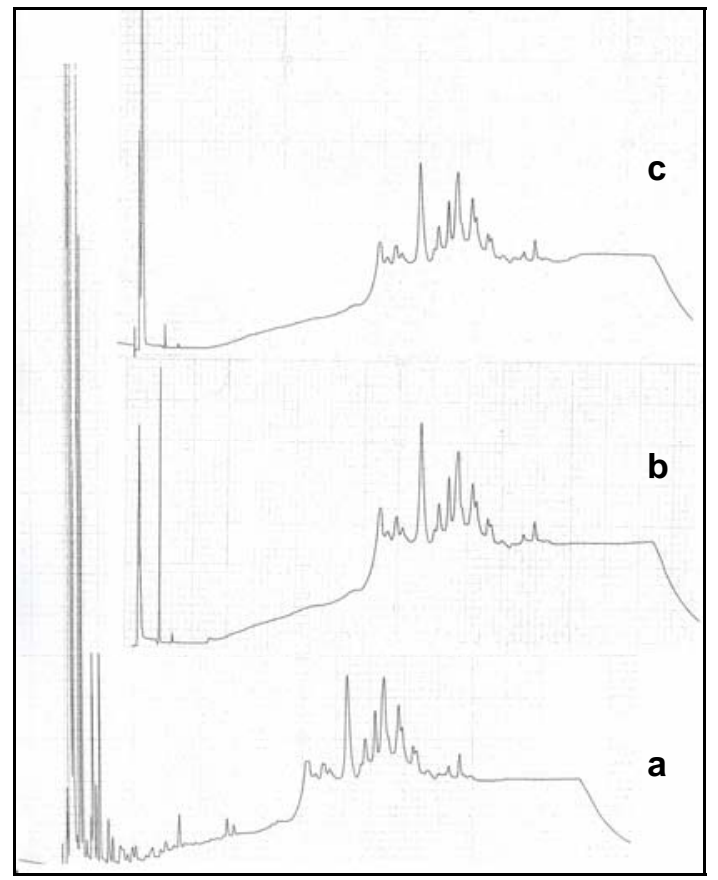

Figure 2. Chromatographs of a) water/fuel, b) washing water, c) eluted water/fuel from the fly ash column.

lar approach. Preliminary study appears to show a complete removal of hydrogen sulfide from water.

\section{ACKNOWLEDGMENTS}

Authors would like to thank the Ohio University Research Challenge Program for funding this project, Enviro-Mont,
Environmental Consulting \& Services, Twin Falls, Idaho, for their field tests, and Mr. Robert Senita, Supervising Engineer, AEP, Conesville, Ohio, for providing fly ash.

\section{REFERENCES}

1. Tarunjit, S. Butalia and Wolfe, William E., Utilization of Ohio Coal Combustion Products, 2001, http://ohioline.osu.edu/aexfact/0330.html

2. Koester, Carolyn J. and Hites, Ronald A. Environ. Sci. Technol., Vol. 26, p. 502 (1992).

3. Dunstan, T.D.J., Mauldin, Robert F., Jinxian, Zhong, Hipps, Anthony, Wehry, D. E.L. and Mamantov, Gleb Environ. Sci. Technol., Vol. 23, p. 303 (1988).

4. Behymer, Thomas D. and Hites, Ronald A. Environ. Sci. Technol., Vol. 22, p. 1311 (1988).

5. Pitts, Jr., James N., Sweetman, Janet A., Ziellnska, Barbara, Atkinson, Roger, Winer, Arthur M. and Hager, William P. Environ. Sci. Technol., Vol. 22, p. 23 (1988).

6. Rostami, H. and Jahanian, S. Fly Ash Offers Cheap Remediation Alternative for Removal of Heavy Metals from Wastewater,

http://www.cleantechindia.com/bishtml/2 10303.50.htm

7. Christopher Amrhein, P.A., Mosher, R.C. Gagajena, Tai Soon Kim and Gholam Hossein Haghnia, www.ucei.berkeley.edu/UCEI/projects/pr 1771.html.

Ohio University Zanesville Zanesville, Ohio 43701 www.zanesville.ohiou.edu

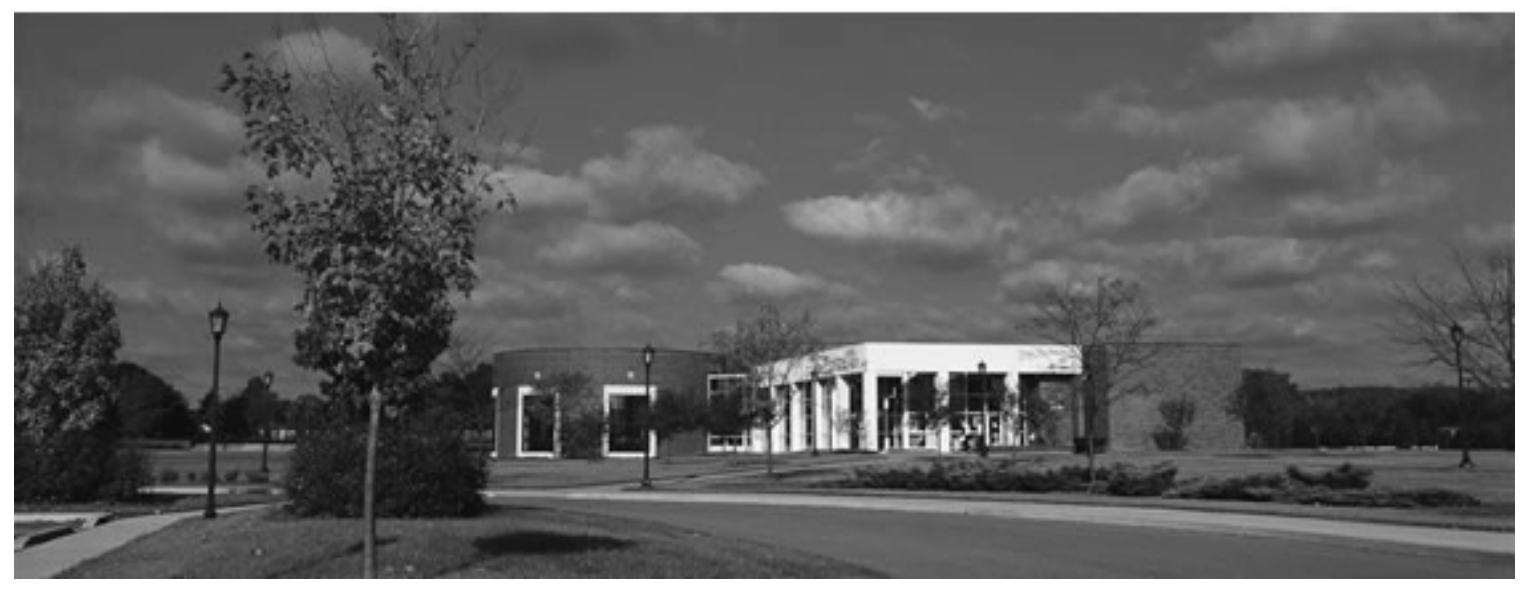




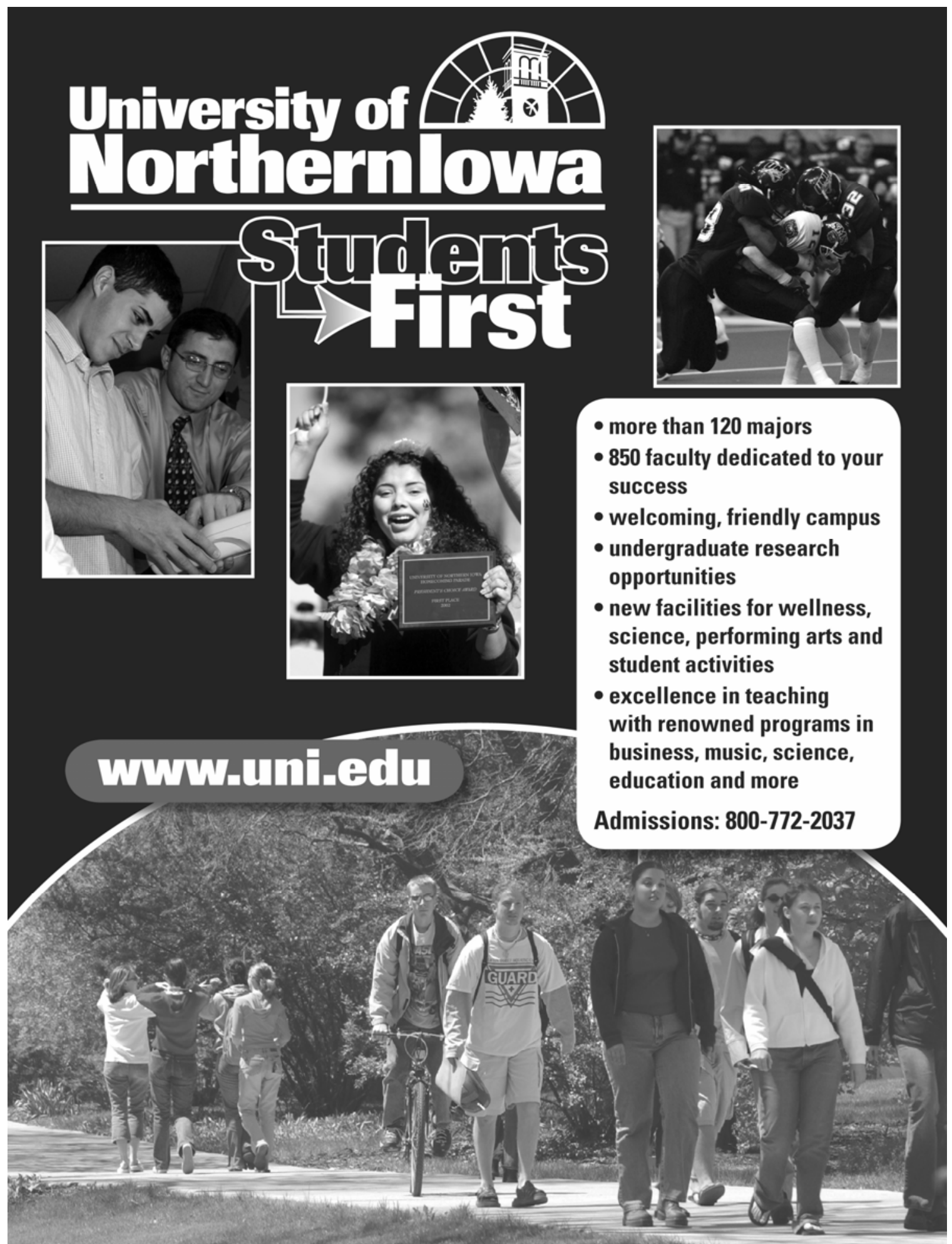

